DOI: 10.2478/romneu-2014-0023

\title{
Massive spontaneous corpus callosal hemorrhage with intraventricular extension
}

\author{
P.N. Harisha ${ }^{1}$, V. Umamaheshwar Reddy ${ }^{2}$, Amit Agrawal ${ }^{3}$, \\ Gopal Kodali ${ }^{4}$
}

\author{
${ }^{1}$ Assistant Professor of Neurosurgery, Department of Neurosurgery, Narayana Medical College \\ Hospital, Chinthareddypalem, Nellore, Andhra Pradesh (India) \\ ${ }^{2}$ Assistant Professor of Radiology, Department of Radiology, Narayana Medical College \\ Hospital, Chinthareddypalem, Nellore, Andhra Pradesh (India) \\ ${ }^{3}$ Professor of Neurosurgery, Department of Neurosurgery, Narayana Medical College Hospital, \\ Chinthareddypalem, Nellore, Andhra Pradesh (India) \\ ${ }^{4}$ Resident of Radiology, Department of Radiology, Narayana Medical College Hospital, \\ Chinthareddypalem, Nellore, Andhra Pradesh (India)
}

\begin{abstract}
Spontaneous hemorrhage into the corpus callosum with intraventricular extension is uncommon. In the present article we describe a case 60 year female who had massive hemorrhage along the corpus callosum involving genu, body of corpus callosum and extending on ventral as well as dorsal aspect of the corpus callosum with intraventricular extension and areas of hypodensities in the body of the corpus callosum and adjacent cerebral cortex. In this case the subarachnoid and corpus callosal hemorrhage probably resulted from the ruptured aneurysms of the anterior cerebral artery.
\end{abstract}

Key words: Corpus callosal hemorrhage, corpus callosal infarct, intra-ventricular bleed, distal anterior cerebral artery.

\section{Introduction}

Spontaneous hemorrhage into the corpus callosum with intraventricular extension is rare with only few reported cases in literature. (1-3) In the present article we describe a case of massive spontaneous corpus callosal hemorrhage with poor outcome.

\section{Case report}

A 60 year old female presented to emergency department with the history of two episodes of projectile vomiting which was followed by loss of consciousness of one day duration. She was not a known hypertensive or diabetic. She had intermittent mild headaches that responded to mild analgesics. She also had 2-3 episodes of syncope from which she spontaneously recovered without any focal deficits and did not seek medical attention. At the time of examination in emergency room her blood pressure was $90 / 70 \mathrm{~mm} / \mathrm{Hg}$. She was in altered sensorium (GCS was E1V2M4), pupils were mid-dilated and sluggishly reacting. Blood investigations including coagulation profile were within normal range. 
As she had labored breathing, endotracheal intubation was performed and ventilator was connected. Her CT scan plain axial images showed massive hemorrhage along the corpus callosum involving genu, body of corpus callosum and extending on ventral as well as dorsal aspect of the corpus callosum. Hemorrhage was extending into the lateral, third and fourth ventricles. There were areas of hypodensities in the body of the corpus callosum and adjacent cerebral cortex (Figures 1 and 2).

Because of poor general condition and neurological status she could not be further investigated and succumbed to massive intracranial hemorrhage.

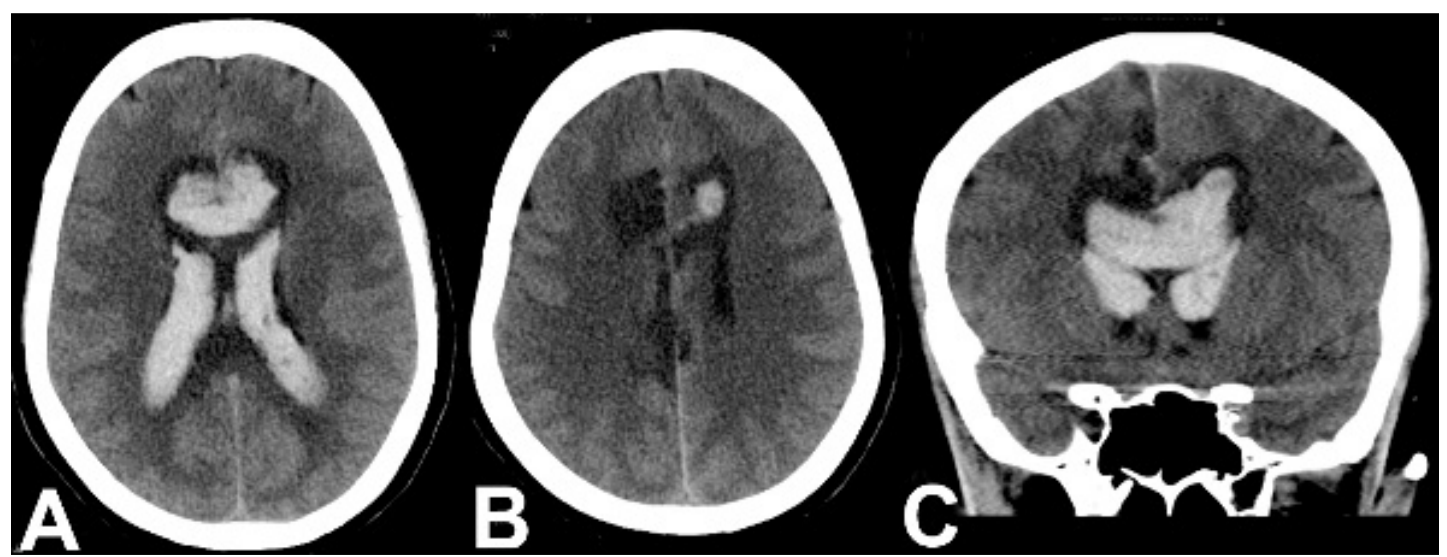

Figure 1 - CT scan plain axial (A and B) and coronal images showing massive hemorrhage along the corpus callosum involving genu, body of corpus callosum and extending on ventral and dorsal aspect of the corpus callosum and into the ventricles, there are areas of cortical hypodensities superior and lateral to the corpus callosum (? Infarcts)

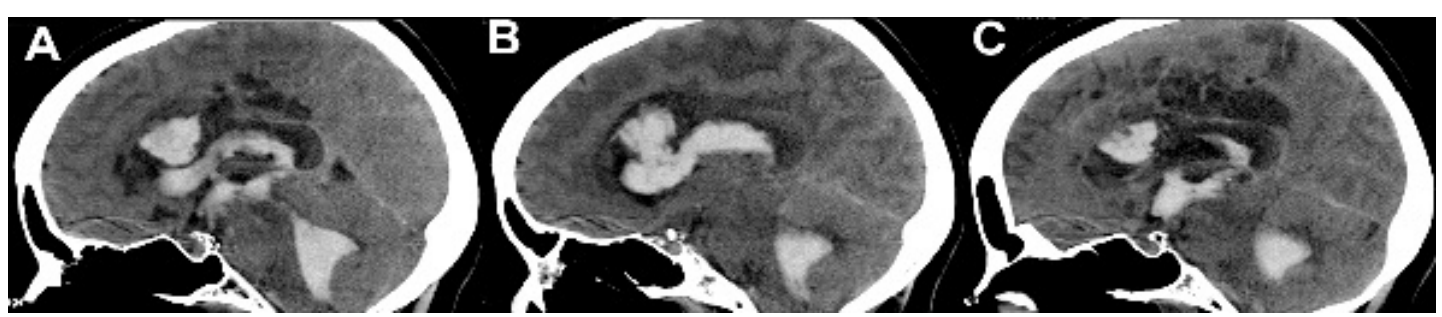

Figure 2 - CT scan sagittal images showing the details and extension of the hemorrhages i.e. massive hematoma in the corpus callosum, intraventricular extension (lateral, third and fourth ventricles) with areas of cortical hypodensities

\section{Discussion}

Corpus callosum is supplied by the pericallosal branch of the anterior cerebral artery (main vas-cular supply to the body), subcallosal and me $\neg$ dial callosal arteries, branches of the anterior com-municating artery (main supply for the anterior portion of the corpus callosum) and the posterior pericallosal artery (branch of the posterior cerebral artery) supplies the splenium. (4) A 
DOI: 10.2478/romneu-2014-0023

number of lesions including aneurysms of the pericallosal artery, giant aneurysms, traumatic brain injury, arteriovenous malformations, intracranial infections and intracranial tumors have been implicated as the cause of spontaneous hemorrhage into the corpus callosum. (1, 2, 4-9) However in spite of all the investigations there may not be any detectable underlying pathology. (1) Subarachnoid hemorrhage resulting from the ruptured aneurysms of the anterior cerebral artery or the pericallosal artery can cause hematomas in the corpus callosum. (2, 3) The highest amount of blood is seen in the distal interhemispheric fissure, pericallosal cistern, and lam $\neg$ ina terminalis cistern. (10) The blood can pass through the lamina terminalis into ventricles and the septum pellucidum and thus appearing on the ventral as well as dorsal aspect of the anterior corpus callosum. $(2,3)$ the reported incidence of intraventricular hemorrhage is $25-30 \%$ of the patients and IVH is more frequently reported with ruptured A2AS and A3 segment aneurysms. (11) The prognosis depends on the size of the hematoma and the prognosis is poor for patients with larger hemorrhages. (9) Patients with smaller hemorrhages without any underlying pathology can recover with conservative management. (1)

\section{Conclusion}

Corpus callosum is very unusual site for spontaneous intracerebral hematoma, numerous etiological factors like aneurysms of the pericallosal artery, giant aneurysms, traumatic brain injury, arteriovenous malformations, intracranial infections and intracranial tumors have been implicated for this uncommon site of bleed. Corpus callosal hemorrhage can dissect into ventricles through the lamina terminalis.

\section{Correspondence:}

Dr Umamaheswara Reddy V

Assistant Professor of Radiology

Department of Radiology

Narayana Medical College Hospital

Chinthareddypalem

Nellore-524003

Andhra Pradesh (India)

Email: mahesh.rd2112@gmail.com

Mobile- +91-9959632228

\section{References}

1. Roditis S. Spontaneous hematoma of the septum pellucidum and corpus callosum: a case report. Romanian Neurosurgery 2011;XVIII:344-348.

2. Fitsiori A, Nguyen D, Karentzos A, Delavelle J, Vargas $\mathrm{M}$. The corpus callosum: white matter or terra incognita. British Journal of Radiology 2011;84:5-18.

3. Jackson A, Fitzgerald J, Hartley R, Leonard A, Yates J. $\mathrm{CT}$ appearances of haematomas in the corpus callosum in patients with subarachnoid haemorrhage. Neuroradiology 1993;35:420-423.

4. Türe U, Yasargil MG, Krisht AF. The arteries of the corpus callosum: a microsurgical anatomic study. Neurosurgery 1996;39:1075-1085.

5. Ogura K, Yamamoto I, Hara M, Suzuki Y, Nakane T, Watanabe M. Computerized tomography of the traumatic hematoma in the corpus callosum.--Report of 2 cases]. No shinkei geka Neurological surgery 1982;10:1299.

6. Shigemori M, Kojyo N, Yuge T, Tokutomi T, Nakashima H, Kuramoto S. Massive traumatic haematoma of the corpus callosum. Acta neurochirurgica 1986;81:36-39.

7. Park D-H, Chung Y-G, Shin I-Y, Lee J-B, Suh J-K, Lee $\mathrm{H}-\mathrm{K}$. Thrombosed giant aneurysm of the pericallosal artery with inconclusive findings of multiple neuroimaging studies. Neurologia medico-chirurgica 2008;48:26-29. 
8. Lehecka $M$, Porras $M$, Dashti R, Niemelä $M$, Hernesniemi JA. Anatomic features of distal anterior cerebral artery aneurysms: a detailed angiographic analysis of 101 patients. Neurosurgery 2008;63:219-228; discussion 228.

9. Lehecka M, Dashti R, Lehto H, Kivisaari R, Niemelä M, Hernesniemi J. Distal anterior cerebral artery aneurysms: Springer, 2010.
10. Stewart C, Lurito J. Ruptured pericallosal aneurysm causing hemorrhage along the fornix. Neuroradiology 2002;44:993-995.

11. Dashti R, Hernesniemi J, Lehto $\mathrm{H}$, et al. Microneurosurgical management of proximal anterior cerebral artery aneurysms. Surgical neurology 2007;68:366-377. 